\title{
Cryopreservation of Vasconcellea quercifolia St.-Hil (Caricaceae) Zygotic Embryos
}

\author{
Cibele M. GALLO ${ }^{1}$, Renato PAIVA², Rodrigo T. FREITAS ${ }^{2}$, \\ Michele V. REIS ${ }^{2 *}$, Diogo P.C. SILVA ${ }^{2}$, Luciano C. SILVA ${ }^{3}$ \\ ${ }^{1}$ Universidade Federal de Alagoas, Centro de Ciências Agrárias (CECA), BR 104, CEP 57100-000, \\ Rio Largo, AL, Brazil; cibele.gallo@hotmail.com \\ ${ }^{2}$ Universidade Federal de Lavras, Campus Universitário, Setor de Fisiologia Vegetal, CEP 37200-000, Lavras, MG, Brazil; \\ renpaiva@dbi.ufla.br; rodrigotfreitas@hotmail.com; mvreis@yahoo.com.br (*correspondingauthor); pedrosacorrea@yahoo.com.br \\ ${ }^{3}$ Universidade Federal da Paraiba, Centro de Biotecnologia, Castelo Branco, CEP 58051-900, \\ João Pessoa, PB, Brazil; lucoutsilva@yahoo.com.br
}

\begin{abstract}
Vasconcellea quercifolia A. St.-Hil. (Caricaceae) is a tropical fruit species native to Brazil, with a great importance in plant breeding programs. The V. quercifolia has a resistance to the main diseases of Caricaceae, Papaya Ringspot Virus (PRSV). Considering its potential, cryopreservation becomes a tool for the conservation of this species. The objective of this paper was to study the cryopreservation of $V$. quercifolia zygotic embryos through dehydration in silica gel. Excised zygotic embryos were dehydrated in silica at 0, 20, 40,80 and 100 minutes and then inoculated in MS medium. The percentage of germinated and recovered embryos, and growth analysis were evaluated, besides water content. Subsequently, they were acclimatized in a growth room with temperature controlled. For cryopreservation, the embryos were excised and dehydrated in silica for 0, 20, 40 and 60 minutes, immersed in Liquid Nitrogen (LN) for 1 hour, thawed in Recovery Solution (RS) and inoculated in MS medium. After 30 days, the percentage of germinated and recovered embryos was evaluated. The silica gel promotes a fast dehydrate of embryos. The results showed that embryo dehydration affected seedling development, and dehydration for over 20 minutes showed a reduction in all evaluated parameters. The plantlets regenerated from embryos dehydrate survive the acclimatization. It was possible to cryopreserve the $V$. quercifolia zygotic embryos when the dehydration time of 20 minutes by silica gel was used.
\end{abstract}

Keywords: Caricaceae; dehydration, in vitro conservation; silica gel; tropical fruit

\section{Introduction}

Vasconcellea quercifolia A. St.-Hil. is a native Brazilian species, belonging to the family Caricaceae. This tropical species presents small fruits with smooth skin and firm pulp, with potential use in the food and pharmaceutical industry (Alamery and Drew, 2014; Faccio et al., 2015).V. quercifolia produces large amount of papain, that is used as a debridant, acts as an anti-inflammatory, and can be used in several healing stages (Falanga, 2002; Torres et al., 2012). Also, $V$. quercifolia has a great importance for its resistance to the Papaya Ringspot Virus (PRSV), one of the main diseases of Caricaceae. This makes it a potential species for use in breeding programs of Caricaceae species, as well as a rootstock (Caetano et al., 2008; Alamery and Drew, 2014; Chaves-Bedoya and Ortiz-Rojas, 2015; KanchanaUdomkan, et al., 2016).
Considering the characteristics of economic interest of Vasconcellea quercifolia, their in vitro conservation is essential for the preservation of the species, as well as a complementary tool for this species multiplication. Among the conservation techniques, cryopreservation, which consists in the preservation of biological material at ultralow temperature $\left(-196^{\circ} \mathrm{C}\right)$ in liquid nitrogen, has been the most outstanding. This technique allows for long-term storage, maintaining all the characteristics of explants indefinitely. Cryopreservation is a promising technique for the preservation of plant diversity of tropical plants (Engelmann et al., 2011; Engelmann and Dussert, 2013; Elliott et al., 2017; Lambardi et al., 2018).

Most plant materials used in cryopreservation contain high amounts of intracellular water being extremely sensitive to freezing injury caused by the formation of ice crystals when exposed to low temperatures (Porto et al., 2014; Wesley-Smith et al., 2014; Pérez-Rodríguez et al., 
64

2017). So, for the successful of cryopreservation, it is essential that the plant material has been dehydration prior cryopreservation. A way to efficiently reduce the water content in the plant material is with the use of the silica gel dehydration that can be used for different material to physical desiccation (Pinto et al., 2016; Pérez-Rodríguez et al., 2017; Carmona-Martín et al., 2018). Since the silica gel technique is simple it becomes more reproducible. This technique shows advantages such as the promotion of uniform desiccation of explants (between and within sample), an accurate dehydration (Pains et al., 2001; Sherlock et al., 2005; Sisunandar et al., 2010). However, the time of desiccation need to be evaluated among species to obtain a high survival rate, besides maintenance of biochemical, physiological and genetic characteristics (Fonseca and Freire, 2003; Michalak et al., 2015; Pinto et al., 2016).

Cryopreservation appears as a technique for the conservation of $V$. quercifolia, with the objective of avoiding the genetic erosion of this material and preserving the species. Given the above, this study has the objective to cryopreserve $V$. quercifolia zygotic embryos using silica gel dehydration.

\section{Materials and Methods}

\section{Dehydration test}

Ripe $V$. quercifolia fruits were collected in Lavras, Southern Minas Gerais, Brazil $\left(21^{\circ} 14\right.$ 'S and $45^{\circ} 00^{\prime} \mathrm{W}$ Gr. and $918 \mathrm{~m}$ altitude). The fruits were washed and taken to a laminar flow chamber for asepsis, where they were immersed in $70 \% \mathrm{v} / \mathrm{v}$ alcohol for one minute, then placed in a $1 \%$ sodium hypochlorite solution with $1 \%$ active chlorine for 10 minutes and washed three times in sterile water. After asepsis, the fruits were depulped, the seeds were immersed in $70 \% \mathrm{v} / \mathrm{v}$ alcohol for 30 seconds and then immersed in a sodium hypochlorite solution with $1 \%$ active chlorine for 5 minutes. After asepsis, the embryos were excised.

Excised zygotic embryos were dehydrated in silica gel for different periods $(0,20,40,60,80$ and 100 minutes) and then inoculated in MS medium (Murashige and Skoog, 1962), supplemented with $30 \mathrm{~g} \mathrm{~L}^{-1}$ sucrose and solidified with $7 \mathrm{~g} \mathrm{~L}^{-1}$ agar and previously autoclaved at $121^{\circ} \mathrm{C}$ for 20 minutes. The $\mathrm{pH}$ of the medium was adjusted to 5.8. The material was kept in the absence of light for seven consecutive days, and then transferred to a growth room at $25 \pm 2{ }^{\circ} \mathrm{C}$, with a 16 -hour photoperiod and a luminous flux density of $48 \mu \mathrm{mol} \mathrm{m} \mathrm{s}^{-1}$ for 45 days. After 45 days, the following parameters were evaluated: (i) germination (\%), recovery (embryos that developed shoots and roots) (\%), (ii) number of green leaves, (iii) seedling length $(\mathrm{cm})$, (iv) root number $(\mathrm{v})$ and length of the largest root $(\mathrm{cm})$. The water content of the zygotic embryos was also determined in the different dehydration periods $(0,20,40,60,80$ and 100 minutes). After determination of initial fresh matter, the embryos were dehydrated and their weight was determined; subsequently, they were completely oven dried at $70^{\circ} \mathrm{C}$ for 72 hours. After this period, the final dry matter of the embryos was verified. With the values of fresh and dry matter at the different dehydration times, the water content of the embryos was determined.

\section{Acclimatization}

After the dehydration process, germinated seedlings were transferred to tubes with commercially available Plantmax substrate with clear plastic bag cover. The seedlings were kept in a growth room at an average temperature of $25 \pm 2{ }^{\circ} \mathrm{C}$. The plastic bag was gradually removed, weekly, until complete withdrawal after 30 days. After the acclimatization period, survival (\%), leaf and root number, plant length and main root length $(\mathrm{cm})$, besides fresh and dry matter $(\mathrm{mg})$, were evaluated.

\section{Cryopreservation}

Zygotic embryos were extracted and dehydrated in periods of $0,20,40$ and 60 minutes. The dehydration periods were chosen taking into account the results found in previous dehydration tests. The embryos were placed in 2$\mathrm{mL}$ cryotubes containing one drop of PVS2 [(Plant Vitrification Solution 2), solution consisting of 30\% glycerol (w/v), 15\% ethylene glycol (w/v) and 15\% DMSO (w/v)] (Sakai et al., 1990). Subsequently, the embryos were immersed in Liquid Nitrogen (LN) at $-196^{\circ} \mathrm{C}$ for at least 30 minutes. The materials were thawed in Recovery Solution [(RS), $0.4 \mathrm{~mol} \mathrm{~L}^{-1}$ sucrose in MS medium] (Sakai $e t$ al., 1990) for 45 minutes at room temperature. After thawing, the cryopreserved embryos were inoculated in MS medium supplemented with sucrose $(0.3 \mathrm{M})$ for 24 hours and kept in a chamber in the absence of light, then transferred to MS medium supplemented with sucrose $(0.09 \mathrm{M})$ and maintained in the absence of light for six days. After this period, the embryos were transferred to the presence of light at a 16-hour photoperiod at $25 \pm 2{ }^{\circ} \mathrm{C}$ and luminous flux density of $48 \mu \mathrm{mol} \mathrm{m} \mathrm{s}^{-2}$ for 30 days. The evaluated parameters were percentage of embryos germinated and recovered (complete seedling formation with shoot and root).

\section{Statistical analysis}

For the dehydration test, three replicates with ten embryos per Petri dish were used per treatment; for the determination of water content, 10 embryos were used per treatment and, for acclimatization, 10 normal plants. For cryopreservation, 30 zygotic embryos were used for each treatment.

The design was completely randomized (CRD), the data were submitted to analysis of variance (ANOVA) and the means were compared by the Tukey test at 5\% significance, using the statistical software SISVAR (Ferreira, 2014).

\section{Results and Discussion}

\section{Dehydration test}

The $V$. quercifolia zygotic embryos had an initial moisture content of $80 \%$. After 20 minutes of dehydration, the zygotic embryos showed a drastic fall to values close to $40 \%$ water, showing not statistical significance from the other dehydration times (Fig. 1).

$V$. quercifolia embryos showed a fast dehydration during first $20 \mathrm{~min}$ and stabilized after this period. Similar results have been reported for Haemanthus montanus (Sershen $e t$ al., 2011), Cocos nucifera L. (Sisunandar et al., 2010), Byrsonima intermedia (Silva et al., 2014), Physalis angulata 
(Faria et al., 2016), Coffee zygoticos embryos (Pinto et al., 2016).

Even though there was no deep decrease in water content after $20 \mathrm{~min}$ of dehydration, with the increase in dehydration time, it was verified a decrease in embryo germination and recovery, opposite from observed in control. The control showed $100 \%$ of germination and recovery. After $40 \mathrm{~min}$ of dehydration, germination and recovery were lower than 50\%, which is considered low (Fig. 2).

The decline in germination and recovery percentage in embryos exposed to the highest periods in silica gel (over 20 minutes) could have occurred due to fast water loss, with a drop of approximately $50 \%$ water content in only 20 minutes.

The low embryo survival from 40 minutes of dehydration possibly occurs due to the stress caused by dehydration, and changes induced in the embryo physiology, biochemistry and genetic stability (Urbanova et al., 2006). Also in H. montanus zygotic embryos was observed that dehydration over a water content optimum induce a decrease in vigour and recover of the seedling (Nadio et al., 2010).

After 45 days from each dehydration time the zygotic embryos kept on in vitro culture were evaluated. It was observed that the different dehydration times in silica gel affected shoot length, leaf and root number, besides the length of the largest $V$. quercifolia root.

The plants resulting from zygotic embryos which showed values close to $40 \%$ water after dehydration was carried out for 20 minutes showed a decreased number of roots and a decrease in root and shoot length, however, for leaf number, the statistical difference was only observed when the embryos were dehydrated from 40 minutes (Fig. 3).

As observed in Fig. 3C and D, the seedlings from zygotic embryos exposed for 20 minutes in silica gel had a larger plant length, and root formation compared to the other dehydration treatments. It can also be observed that the leaf number decreased as the dehydration time increased.

These results demonstrate that not only did the dehydration of $V$. quercifolia zygotic embryos cause a decrease in germination and recovery, but also in seedling growth and development, thus leading to lower seedling growth in the shoot and root as dehydration time increased.
Similar results were also obtained in a study with Quercus robur plumules, in which the authors observed the effect of dehydration in silica gel, finding that plumules that had been dehydrated for 50 minutes showed a reduction in survival rate from $18 \%$ to about $0 \%$, after drying for 70 minutes (Chmielarz et al., 2011). The decrease in survival rate was also reported by Scocchi et al. (2007), who obtained only $27 \%$ survival of Melia azedarach L. somatic embryos, which were kept in silica gel for four hours.

After in vitro culture, the plants where acclimated and 30 days after acclimatization, it was observed that $100 \%$ plant survival in all treatment. Plants from embryos that did not undergo dehydration showed higher growth during acclimatization when compared with plants originally obtained from previously dehydrated embryos. In general, among the dehydration treatments, embryos dehydrated for 20 minutes had plants with the best characteristics for the analyzed variables, when compared to plants with greater dehydrated embryos time (Fig. 4).

In relation to shoot length, plants from embryos that were not dehydrated had a better result, $7.8 \mathrm{~cm}$ (Fig. 4A). Regarding leaf number, there was no significant difference among the treatments with $0,20,40$ and 80 minutes dehydration, with a mean of 3.1 leaves per plant (Fig. 4B). As for fresh and dry matter, plants from the dehydration periods of 20 and 40 minutes showed higher mean fresh ( 0.34 and 0.28 , respectively) and dry matter ( 0.05 and 0.03 , respectively). In relation to root number and length, plants from embryos dehydrated for 0 and 20 minutes had the best means (Fig. 4D).

Acclimatization is a delicate stage and the embryos were submitted to a dehydration process. Therefore, in addition to being sensitive, the seedlings from the in vitro culture under study are possibly under stress due to water loss. This stress during acclimatization is also due to the nondevelopment of a thick cuticle, which allows a high cuticular transpiration rate, considering that the cell walls of plants grown in vitro do not have the necessary rigidity to support the new plant, sometimes compromising a successful acclimatization (Silva et al., 2015; Faria et al., 2016). But, the plants regenerated from $V$. quercifolia zygotic embryos dehydrated survived to acclimatization stage e presented good development. This demonstrates the rusticity and developmental plasticity of this species.

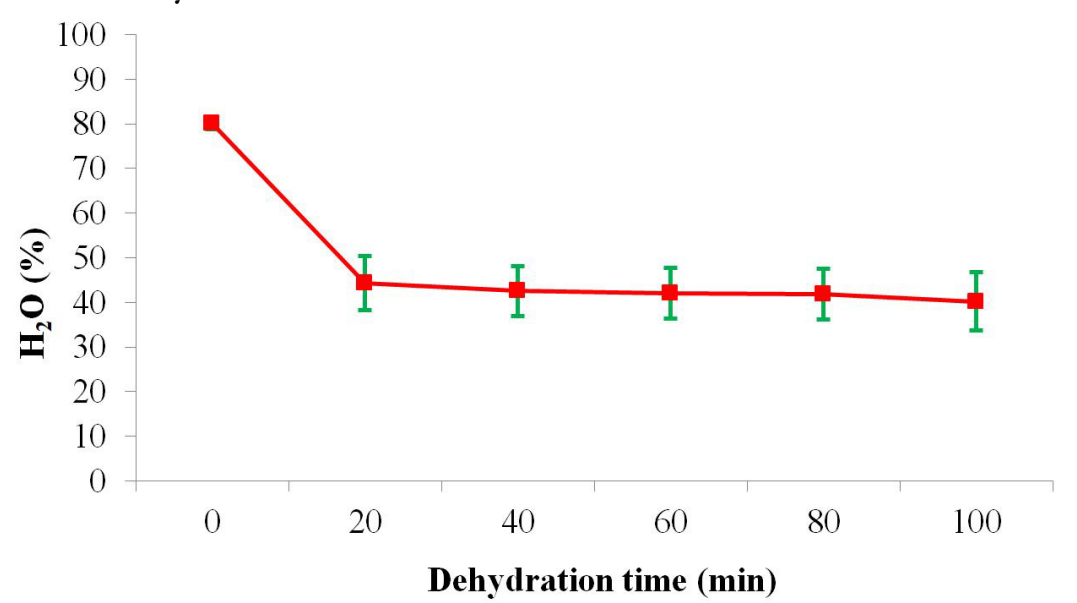

Fig. 1. Moisture content of $V$. quercifolia embryos after dehydration for different periods (min) in silica gel 


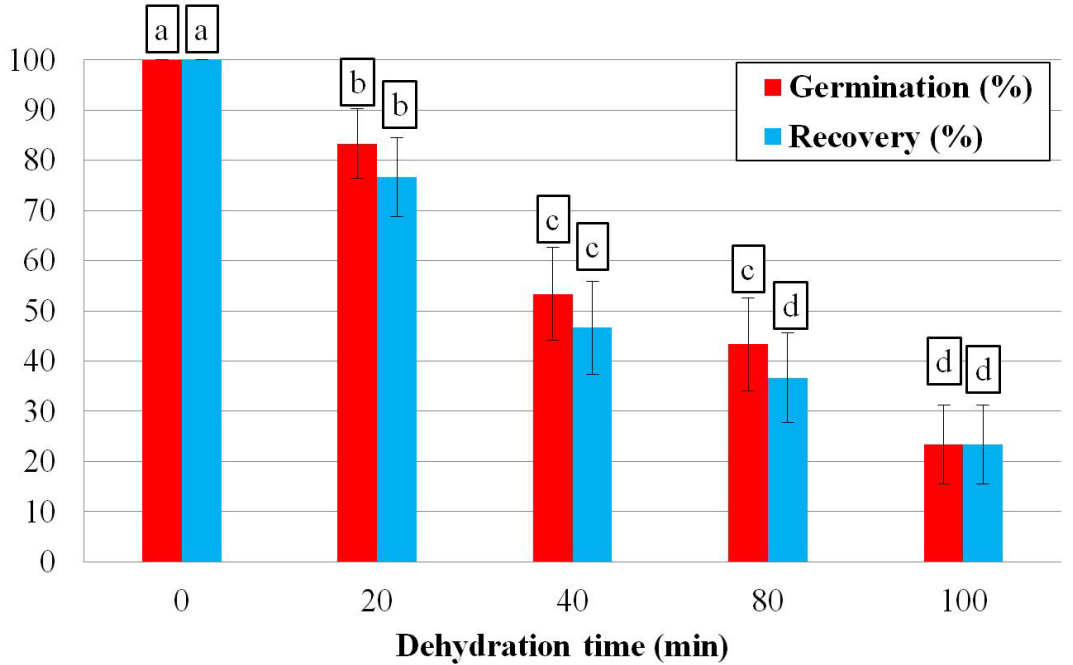

Fig. 2. Germination and recovery percentage of zygotic embryos at different dehydration periods in silica gel

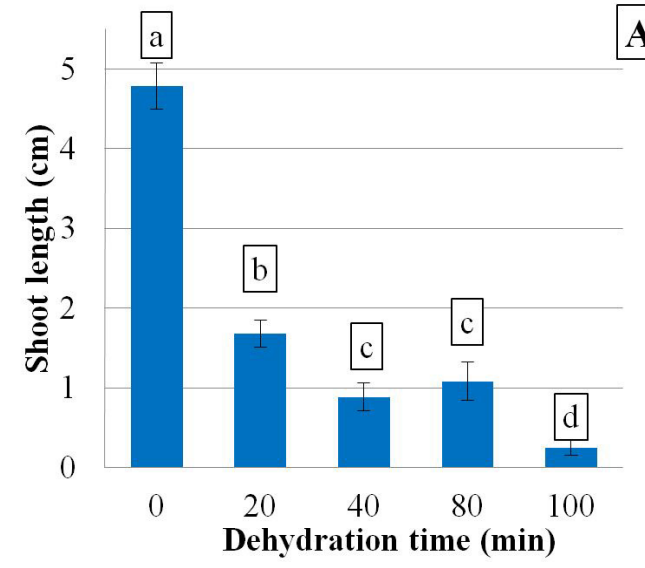

A
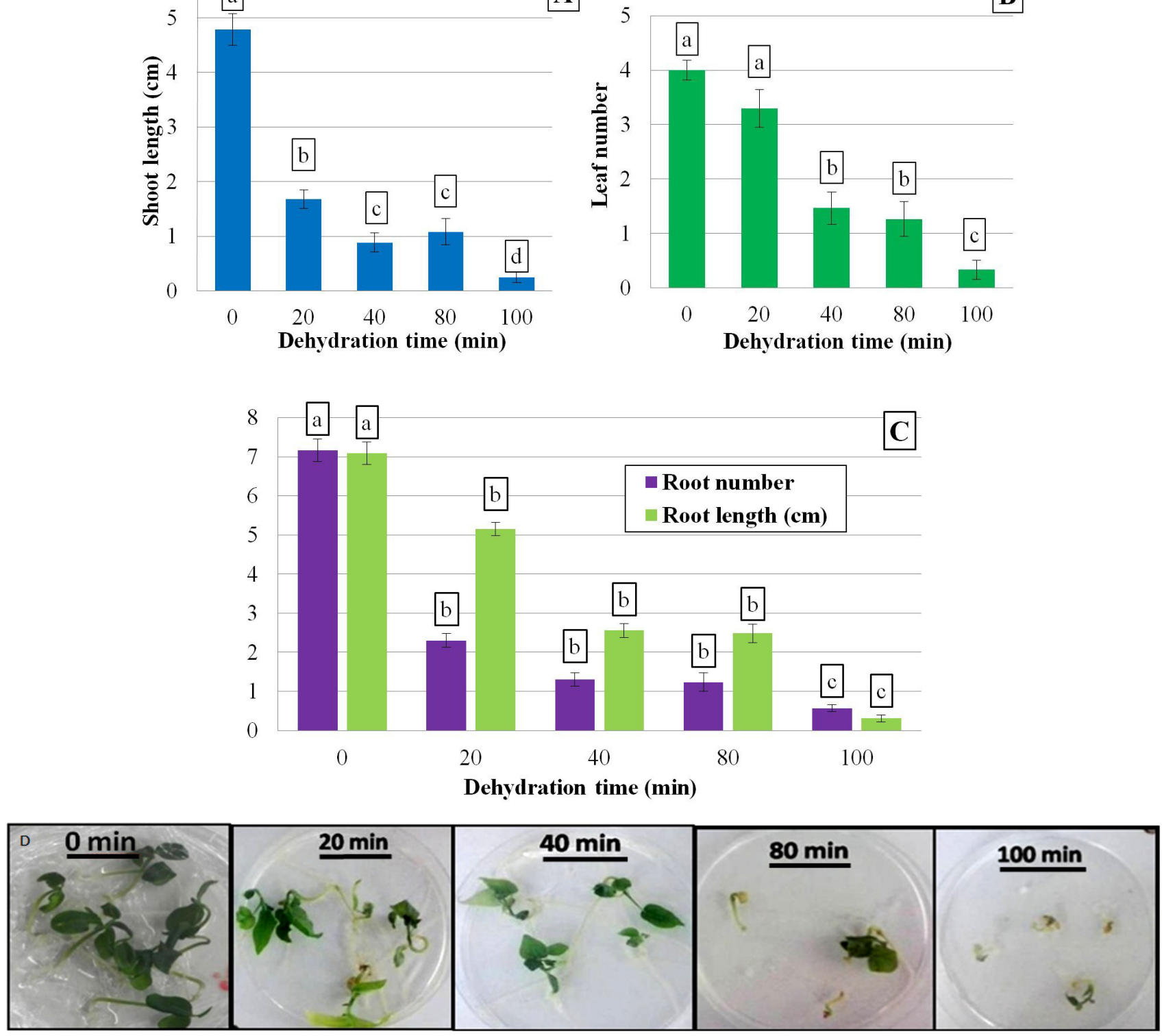

Fig. 3. $V$. quercifolia plants from embryos dehydrated in silica gel for different periods after 45 days of acclimatization. Shoot length (A), leaf number (B), root number and length (C); seedlings from embryos dehydrated in silica gel after 30 days 

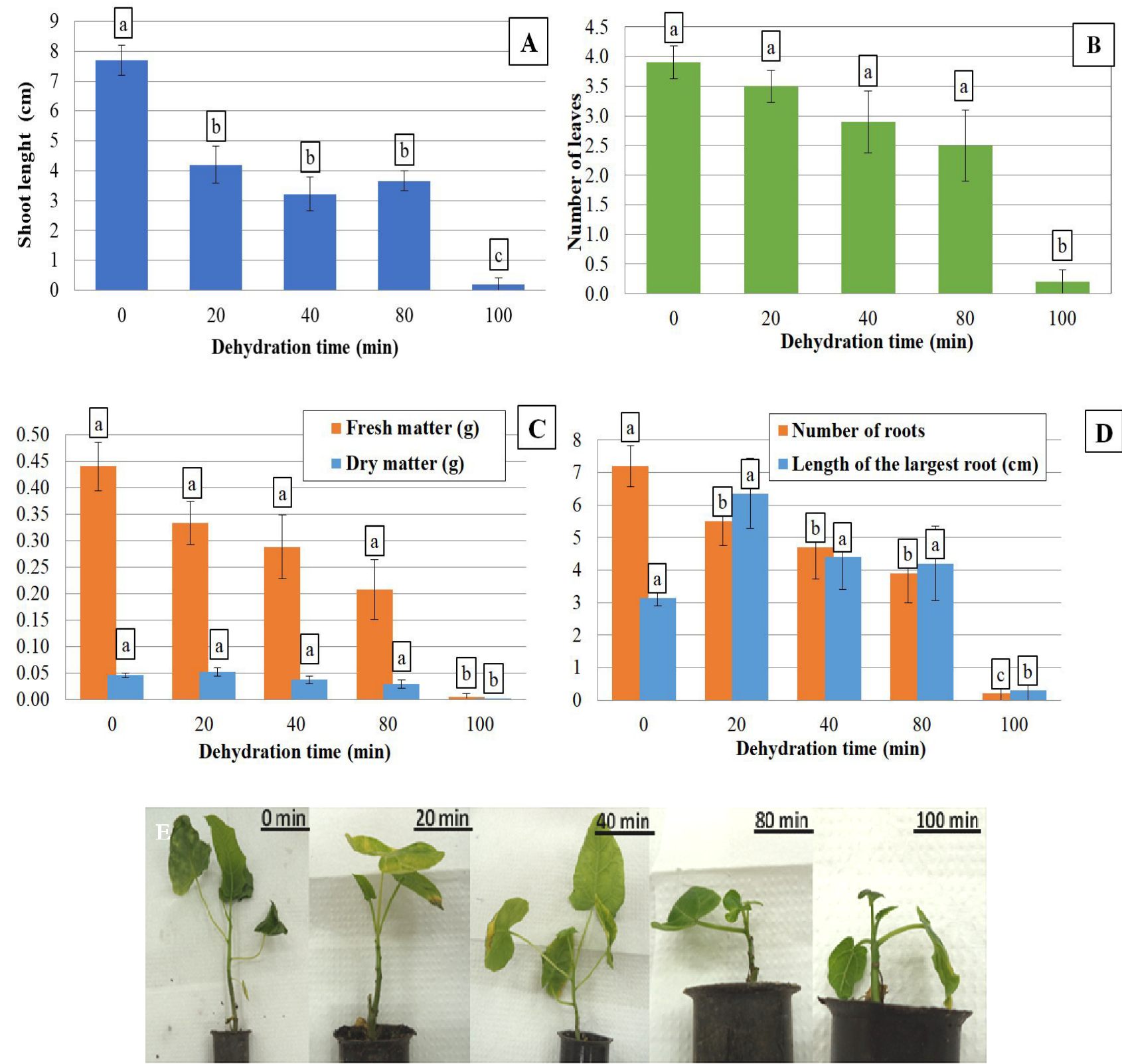

Fig. 4. $V$. quercifolia plants from embryos dehydrated for different periods in silica gel after 30 days of acclimatization. Shoot length $(\mathrm{A})$, leaf number $(\mathrm{B})$, fresh and dry matter $(\mathrm{C})$, root number and length $(\mathrm{D})$; plant appearance

\section{Cryopreservation}

The dehydration of $V$. quercifolia zygotic embryos is a crucial step before cryopreservation, since embryos that were not dehydrated did not survive liquid nitrogen exposure.

The highest germination rate was observed in the treatment in which the embryos were cryopreserved after dehydration for 20 minutes in silica gel, resulting in a germination rate of $26 \%$ (Fig. 5), followed by the treatment using 40 minutes of dehydration, with $16 \%$. However, for recovery, only the treatment with 20 minutes of dehydration presented recovered embryos after cryopreservetion (6.7\%).

In general, embryos contain high amounts of intracellular water and are, therefore, extremely sensitive to freezing injury caused by the formation of ice crystals when exposed to low temperatures (Porto et al., 2014; WesleySmith et al., 2014; Pérez-Rodríguez et al., 2017). Exposure to these low temperatures is also highly stressful for these explants, and may cause metabolic changes; thus, favourable conditions after cultivation are necessary.

The low recovery rate possibly occurred due to the complexity and sensitivity of the tissues that make up the embryo, according to Engelmann (2011), these are the factors that limit germination and recovery of zygotic embryos from species sensitive to dehydration and freezing in liquid nitrogen. As an example, these changes occur in several organelles such as mitochondria, endoplasmic reticulum and Golgi complex, compromising embryo metabolism (Sershen et al., 2012). 


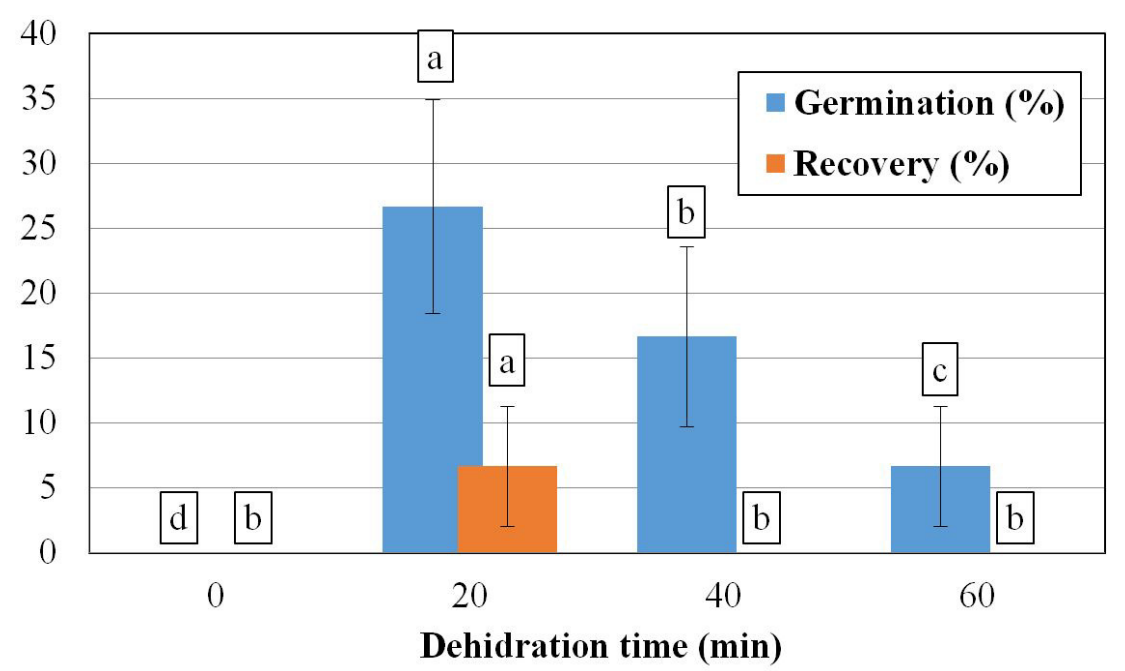

Fig. 5. Percentage of zygotic embryos germinated and recovered after cryopreservation using different dehydration periods in silica gel

The dehydration process has to be sufficient to avoid the formation of ice crystals during the contact of the plant material with ultra-low temperatures. Therefore it is important to avoid the excessive water efflux, which can cause cell death during the dehydration process, and find the minimum of water needed to seedling formation takes place (Freitas et al., 2016).

\section{Conclusions}

It was possible to cryopreserve the $V$. quercifolia zygotic embryos when the dehydration time of 20 minutes by silica gel was used. When dehydration was carried out for more than 20 minutes, although germination was obtained, seedling recovery was not observed after cryopreservation. Due to the decline in the evaluated parameters after cryopreservation process, other studies are suggested to optimize the dehydration time or conditions after cryopreservation of $V$. quercifolia embryos, aiming to improve the rate of recovered embryos after cryopreservation.

\section{Acknowledgements}

This work was supported by the Conselho Nacional de Desenvolvimento Científico e Tecnológico (CNPq), Fundação de Amparo à Pesquisa de Minas Gerais (FAPEMIG), and Coordenação de Aperfeiçoamento de Pessoal de Nível Superior (CAPES).

\section{References}

Alamery S, Drew R (2014). Studies on the genetics of prsv-p resistance genes in intergeneric hybrids between Carica papaya and Vasconcellea quercifolia. Acta Horticulturae 1022:55-61.

Caetano MC, Burbano TCL, Sierra CLS, Tique CAP, Nunes DGC (2008). Citogenética de especies de Vasconcellea (Caricaceae). Acta Agronomy 57:241-245.
Carmona-Martín E, Regalado JJ, Perán-Quesada R, Encina CL (2018). Cryopreservation of rhizome buds of Asparagus officinalis L. (cv. Morado de Huétor) and evaluation of their genetic stability. Plant Cell, Tissue and Organ Culture 133(3):395-403.

Chaves-Bedoya G, Ortiz-Rojas LY (2015). Genetic variability of Papaya ringspot virus isolates in Norte de Santander-Colombia. Agronomía Colombiana33(2):184-193.

Chmielarz P, Michalak M, Palucka M, Wasilenczyk U (2011). Successful cryopreservation of Quercus robur plumules. Plant Cell Reports, 30:1405-1414.

Elliott GD, Wang S, Fuller BJ (2017). Cryoprotectants: A review of the actions and applications of cryoprotective solutes that modulate cell recovery from ultra-low temperatures. Cryobiology 76:74-91.

Engelmann F (2011). Use of biotechnologies for the conservation of plant biodiversity. In vitro Cellular \& Developmental Biology-Plant 47:5-16.

Engelmann F, DussertS (2013). Cryopreservation. In : Normah MN, Chin HF, Reed BM (Eds). Conservation of Tropical Plant Species. Springer Publication, New York.

Facico C, Machado RAF, Souza LM, Zoldan SR, Quadri MGN (2015) Characterization of the mucilage extracted from jaracatiá (Carica quercifolia (A.St. Hil.) Hieron). Carbohydrate Polymers 131:370-376.

Falanga V (2002). Wound bed preparation and the role of enzymes: a case for multiple actions of therapeutic agents. Wounds 14:47-57.

Faria CVN, Paiva R, Freitas RT, Figueiredo JRM, Silva DPC, Reis MV (2016). Cryopreservation of Physalis angulata L. seeds through dehydration on silica gel. Plant Cell Culture \& Micropropagation 12(2):27-33.

Ferreira DF (2014). Sisvar: A guide for its bootstrap procedures in multiple comparisons. Ciênciae Agrotecnologia 38:109-112.

Fonseca SCL, Freire HB (2003). Sementes recalcitrantes: problemas na póscolheita. Bragantia 62(2):297-303.

Freitas RT, Paiva R, Sales TS, Silva DPC, Reis MV, Souza AC, Rosa SDVF (2016). Criopreservation of Coffea arabica L. zygotic embryos by vitrification. Notulae Botanicae Horti Agrobotanici Cluj-Napoca 
$44(2): 445-451$.

Kanchana-Udomkan C, Drew RA, Ford R (2016). A kinase gene potentially implicated in resistance to Papaya ringspot virus in Vasconcellea quercifolia. Acta Horticulturae 1111:41-48.

Lambardi M, Ozudogru EA, Barberini S, Danti R (2018). Strategies for fast multiplication and conservation of forest trees by somatic embryogenesis and cryopreservation: a case study with cypress (Cupressus sempervirens L.).Notulae Botanicae Horti Agrobotanici Cluj-Napoca 46(1):32-38.

Michalak M, Plitta BP, Tylkowski T, Chmielarz P, Suszka J (2015). Desiccation tolerance and cryopreservation of seeds of black poplar (Populus nigra L.), a disappearing tree species in Europe. European Journal of Forest Research 134:53-60.

Murashige T, Skoog F (1962). A revised medium for rapid growth and biomassay with tobacco tissue cultures. Physiologia Plantarum 15(3):473-479.

Naidoo S, Pammenter NW, Berjak P (2011). Effects of partial dehydration of recalcitrant Haemanthus montanus zygotic embryos on vigour of recovered seedlings. South African Journal of Botany 77(1):193-202.

Panis B, Swennen R, Engelman F (2001) Cryopreservation of plant germplasm. Acta Horticulturae 650:79-86.

Pérez-Rodríguez JL, Escriba RCR, González GYG, Olmedo GJL, Martínez-Montero ME (2017). Effect of desiccation on physiological and biochemical indicators associated with the germination and vigor of cryopreserved seeds of Nicotiana tabacum L. cv. Sancti Spíritus 96. In Vitro Cellular \& Developmental Biology-Plant 53(4):440-448.

Pinto MS, Paiva R, Silva DPCD, Santos PAA, Freitas RTD, Silva LC (2016). Cryopreservation of coffee zygotic embryos: dehydration and osmotic rehydration. Ciência Agrotecnologia 40(4):380-389.

Porto JMP, Paiva R, Campos NA, Reis MV, Souza AC, Santos PAA, Braga FT (2014). Cryopreservation of seeds of barbatimão with different water contents. Australian Journal of Basic and Applied Sciences $8(13): 250-256$.

Sakai S, Kobayashi IO (1990). Cryopreservation of nucellar cells of navel orange (Citrus Sinensis Osb Var Brasiliensis Tanaka) by vitrification. PlantCell Reports 9:30-33.
Scocchi A, Vila S, Mroginski L, Engelmann F (2007). Cryopreservation of somatic embryos of paradise tree (Melia azedarach L). CryoLetters 28(4):281-290.

Sershen B, Varghese B, Pammenter NW, Berjak P (2012). Rate of dehydration, state of subcellular organization and nature of cryoprotection are critical factors contributing to the variable success of cryopreservation: studies on recalcitrant zygotic embryos of Haemanthusmontanus. Protoplasma 249:171-186.

Sherlock G, Block W, Benson EE (2005).Thermal analysis of the plant encapsulation-dehydration cryopreservation protocol using silica gel as the desiccant. CryoLetters 26(1):45-54.

Silva LC, Paiva R, Swennen R, Edwige A, Panis B (2014). Cryopreservation of Byrsonima intermedia embryos followed by room temperature thawing. ActaScientiarum Agronomy 36(3):309-315.

Silva DPC, Paiva PDO, Paiva R, Alves E, Porto JMP, Reis MV (2015). Anatomic aspects of gerbera plants during acclimatization. Plant Cell Culture 11(1):27-32.

Sopade PA, Samosir YM, Rival A, Adkins SW (2010). Dehydration improves cryopreservation of coconut (Cocos nucifera L.). Cryobiology 61(3):289-296.

Torres MJ, Trejo SA, Obregón WD, Avilés FX, López LM, Natalucci CL (2012). Characterization of the proteolytic system present in Vasconcelleaquercifolia latex. Planta236:1471-1484.

Urbanova M, Kosuth J, Cellarova E (2006). Genetic and biochemical analysis of Hypericum perforatum L. plants regenerated after cryopreservation. Plant Cell Reports 25:140-147.

Wesley-Smith J, Berjak P, Pammenter NW, Walters C (2014). Intracellular ice and cell survival in cryo-exposed embryonic axes of recalcitrant seeds of Acer saccharinum: An ultrastructural study of factors affecting cell and ice structures. Annals of Botany 113(4):695-709. 